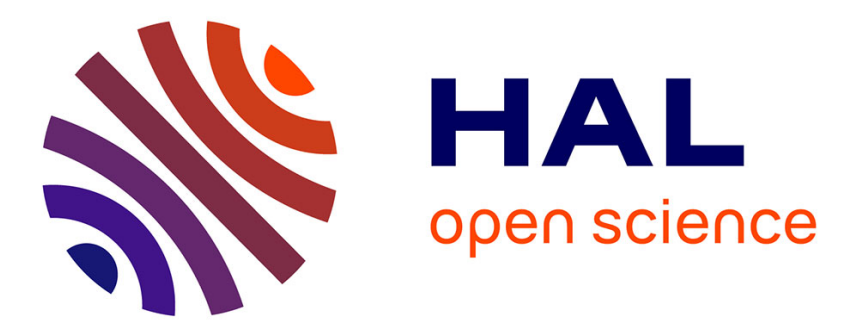

\title{
Modelling the kinetics of transesterification reaction of sunflower oil with ethanol in microreactors
}

\author{
Romain Richard, Sophie Thiebaud-Roux, Laurent E. Prat
}

\section{To cite this version:}

Romain Richard, Sophie Thiebaud-Roux, Laurent E. Prat. Modelling the kinetics of transesterification reaction of sunflower oil with ethanol in microreactors. Chemical Engineering Science, 2013, vol. 87, pp. 258-269. 10.1016/j.ces.2012.10.014 . hal-00757631

\section{HAL Id: hal-00757631 \\ https://hal.science/hal-00757631}

Submitted on 27 Nov 2012

HAL is a multi-disciplinary open access archive for the deposit and dissemination of scientific research documents, whether they are published or not. The documents may come from teaching and research institutions in France or abroad, or from public or private research centers.
L'archive ouverte pluridisciplinaire HAL, est destinée au dépôt et à la diffusion de documents scientifiques de niveau recherche, publiés ou non, émanant des établissements d'enseignement et de recherche français ou étrangers, des laboratoires publics ou privés. 


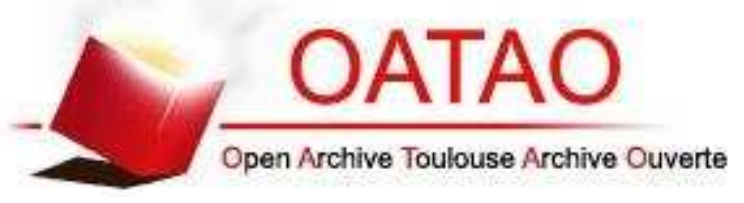

Open Archive Toulouse Archive Ouverte (OATAO)

OATAO is an open access repository that collects the work of Toulouse researchers and makes it freely available over the web where possible.

This is an author-deposited version published in: http://oatao.univ-toulouse.fr/ Eprints ID: 6883

To link to this article: DOI:10.1016/j.ces.2012.10.014

http://dx.doi.org/10.1016/j.ces.2012.10.014

\section{To cite this version:}

Richard, Romain and Thiebaud-Roux, Sophie and Prat, Laurent E. Modelling the kinetics of transesterification reaction of sunflower oil with ethanol in microreactors. (2013) Chemical Engineering Science, vol. 87. pp. 258-269. ISSN 0009-2509

Any correspondence concerning this service should be sent to the repository administrator: staff-oatao@inp-toulouse.fr 


\title{
Modelling the kinetics of transesterification reaction of sunflower oil with ethanol in microreactors
}

\author{
Romain Richard ${ }^{\mathrm{a}, \mathrm{b}, \mathrm{c}, \mathrm{d}}$, Sophie Thiebaud-Roux ${ }^{\mathrm{a}, \mathrm{b}}$, Laurent Prat ${ }^{\mathrm{c}, \mathrm{d}, *}$ \\ a Université de Toulouse, INP-ENSIACET, LCA (Laboratoire de Chimie Agro-Industrielle), F-31030 Toulouse, France \\ b INRA, UMR 1010 CAI, F-31030 Toulouse, France \\ ${ }^{\mathrm{C}}$ Université de Toulouse; INP, UPS; Laboratoire de Génie Chimique; 4, allée Emile Monso, F-31030 Toulouse cedex 4, France \\ ${ }^{\mathrm{d}}$ CNRS; Laboratoire de Génie Chimique; F-31030 Toulouse, France
}

\section{H I G H L I G H T S}

- The biodiesel produced from sunflower oil and ethanol is of $100 \%$ renewable origin.

- The transesterification reaction was carried out in continuous microreactors.

- Kinetic data were acquired from the first seconds of the reaction.

- Reaction kinetics and mass transfer parameters were identified.

- The model was used to simulate other operating conditions (glycerol removal).

\section{Keywords:}

Biodiesel

Transesterification

Multiphase reactions

Microstructure

Parameter identification

Simulation

\begin{abstract}
A B S T R A C T
Transesterification reaction of vegetable oil with ethanol leads to ethyl esters, used to date for applications principally in food and cosmetic industry. To open the application field to biofuels (to substitute current fuels resulting from fossil resources), the process efficiency has to be developed to be economically profitable. In this work, the sunflower oil ethanolysis was performed in a micro-scaled continuous device, inducing better control for heat and mass transfer in comparison with batch processes. Moreover, this device ensures kinetic data acquisition at the first seconds of the reaction, which was not feasible in a conventional batch process. These data were used to model occurring phenomena and to determine kinetic constants and mass transfer coefficients. A single set of these parameters is able to represent the evolution of the reaction media composition function of time for five ethanol to oil molar ratios $(6.0,9.0,16.2,22.7$ and 45.4). The model was validated in reaction and diffusion mode. Finally, it was subsequently used to simulate reactions with other operational conditions and to propose other process implementation.
\end{abstract}

\section{Introduction}

Biodiesel can be produced from vegetable oils, animal fats, and waste cooking oils by transesterification (Demirbas and Karslioglu, 2007; Encinar et al., 2007; Kouzu and Hidaka, 2012) with an alcohol (alcoholysis) in order to substitute fossil fuels. Many works have used methanol (Darnoko and Cheryan, 2000; Fukuda et al., 2001; Sharma and Singh, 2008; Srivastava and Verma, 2008) as alcohol reactant which is mainly produced by oxidation processes of methane, a natural gas component, hence a non-renewable energy. Ethanol, and particularly bioethanol from sugar cane, sugar beet or corn, is preferable to methanol due to its superior dissolving power

\footnotetext{
* Corresponding author at: Université de Toulouse; INP, UPS; Laboratoire de Génie Chimique; 4, allée Emile Monso, F-31030 Toulouse cedex 4, France. Tel.: + 335343237 11; fax: + 33534323697 .

E-mail address: laurent.prat@ensiacet.fr (L. Prat).
}

for vegetable oils, low toxicity and its renewable origin. Various factors such as free fatty acid (FFA) content, water content, type/ amount of catalyst, vegetable oil to alcohol molar ratio, or temperature (Freedman et al., 1984; Darnoko and Cheryan, 2000; Meher et al., 2006; Sharma et al., 2008) can affect the process. This transesterification leads to high conversion of triglycerides (TG) into ethyl esters (Marjanović et al., 2010) with diglycerides (DG) and monoglycerides (MG) as reaction intermediates and glycerol as by-product. Indeed, the overall process is a sequence of three consecutive steps, which are reversible reactions. In the first step, diglycerides (DG) are obtained from triglycerides (TG); monoglycerides (MG) are then produced from diglycerides and in the last step, glycerol $(G)$ is obtained from monoglycerides. In all these reactions, ethyl esters are produced (Fig. 1).

Ethanolysis is generally conducted in batch reactors (Encinar et al., 2007; Marjanović et al., 2010; Richard et al., 2011). According to the reaction scheme and the thermokinetic properties, the limits 

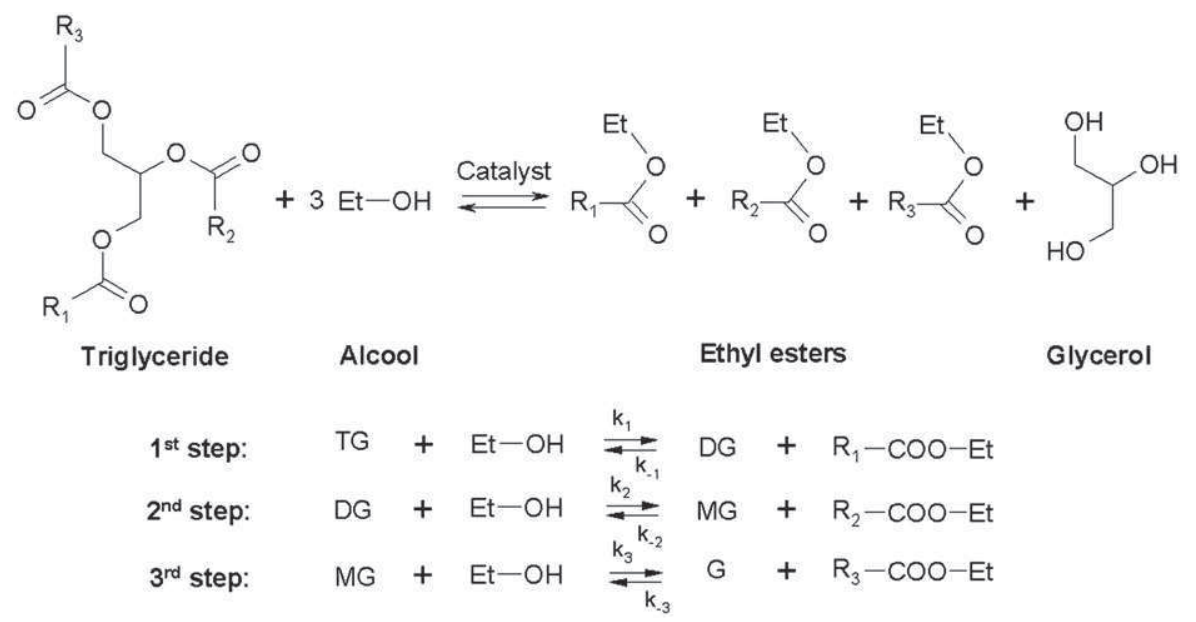

Fig. 1. Global transesterification reaction and its three consecutive steps (where $R_{1}, R_{2}, R_{3}$ are long chain alkyl groups).

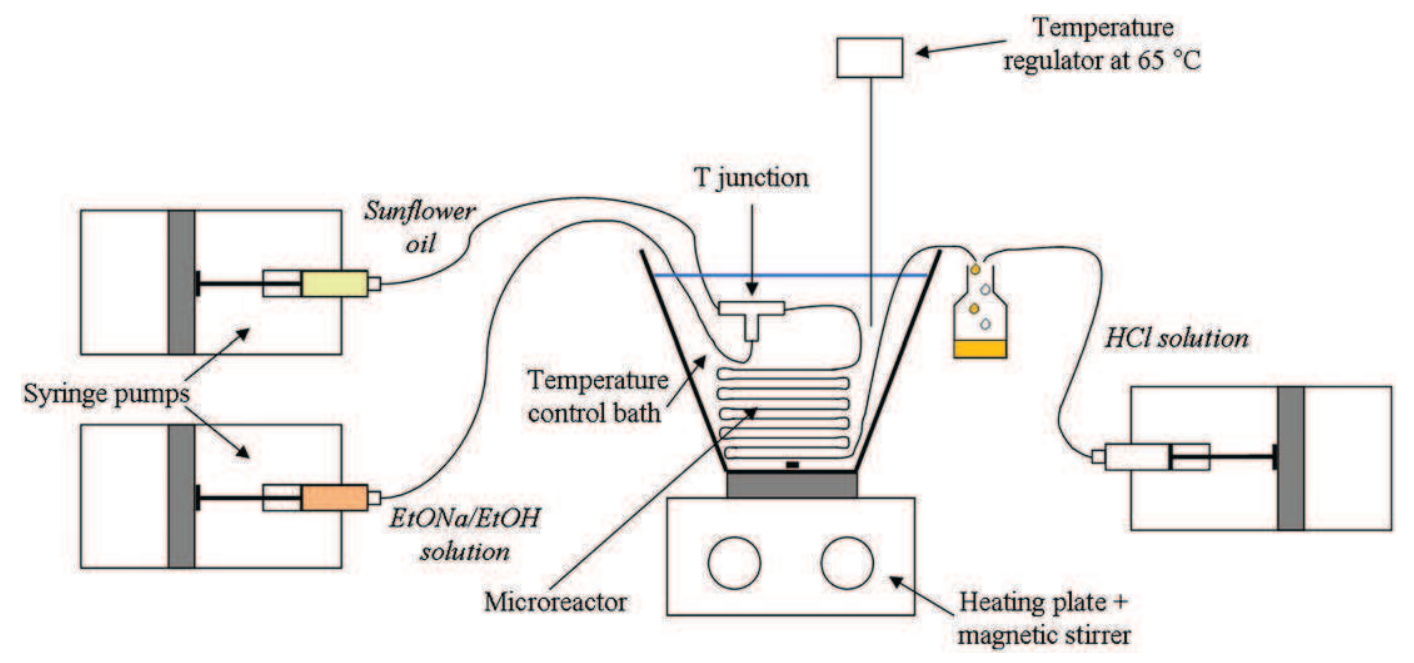

Fig. 2. Experimental set-up of the transesterification reaction carried out in a microreactor.

of current batch processes can be overcome by carrying out continuous processes in order to withdraw existing obstacles of batch processes such as numerous steps, secondary reactions, stable equilibria and difficulties to separate the reaction products. The studied system is complex due in particular to phase equilibrium changes as well as simultaneous presence of various phenomena (mixing, heat and mass transfers, principal and competitive reactions) which have to be precisely controlled. Therefore, for transposition to a continuous process, microreactors which enable acquisition of numerous data, appear as the appropriate tool. Several studies on methanolysis using microreactors have recently been published (Sun et al., 2008, 2009; Wen et al., 2009; Qiu et al., 2010; Xie et al., 2012). The system is complex due to changing phase equilibria (Guan et al., 2010): two immiscible phases are present at the beginning (vegetable oil and methanol), then a single phase appears after a few minutes of reaction. Finally, two phases are obtained at the end of the reaction, majorly composed of methyl esters and glycerol. Hence, to properly design a continuous process, numerous data have been acquired in this study, in particular at low characteristic times. We transferred the batch ethanolysis of high oleic sunflower oil into a continuous microstructured device, which induces a better control of heat and mass transfers. Various parameters were studied, notably the initial ethanol to oil molar ratio. The experimental data obtained by gas chromatography analyses of the reaction media as a function of reaction time ensure the modelling of chemical kinetics and mass transfer phenomena for the transesterification reaction. Kinetics constants and mass transfer coefficients were then calculated in order to match experimental data with modelling data.

\section{Transesterification reaction carried out in microreactors}

\subsection{Materials and methods}

High oleic sunflower oil was obtained from ITERG (Pessac, France). Its fatty acid composition (\% by weight) is as follows: $3.5 \%$ palmitic acid, $3.0 \%$ stearic acid, $87.6 \%$ oleic acid, $4.9 \%$ linoleic acid and $1.2 \%$ other acids. Its mean molecular weight is 882.9 $\mathrm{g} / \mathrm{mol}$ and its acid value is 0.57 . Hydrochloric acid (analytical quality, $3.7 \%$ solution in water) and sodium ethoxide (analytically pure, $21 \mathrm{wt} \%$ in ethanol) were purchased from Acros Organics; absolute ethanol (99.95\%) and cyclohexane (HPLC grade) were supplied by Scharlau. $N$-methyl- $N$-trimethylsilyl-heptafluorobutyramide (MSHFBA) and methylimidazole (MI) were purchased, respectively from Macherey Nagel and Sigma-Aldrich.

The transesterification reaction was performed in circular PFA (PerFluoroAlkoxy) tubes (1/16" OD, 0.02" ID). These PFA tubes were dipped in a temperature-controlled water bath to maintain 
the targeted microreactor temperature $\left(65^{\circ} \mathrm{C}\right.$, close to the boiling point of ethanol). Transesterification of high oleic sunflower oil was carried out by using the following procedure: liquids (oil and a solution of EtONa in EtOH) were injected by syringe-pumps with perfect flow control. The experimental set-up is presented in Fig. 2. Several ethanol to oil molar ratios have been tested $(6.0,9.0,16.2$, 22.7, and 45.4) with the same amount of catalyst ( $1 \mathrm{wt} \%$ compared to oil mass). After a coaxial introduction of the fluids through a $\mathrm{T}$-junction (inner diameter of $500 \mu \mathrm{m}$ ), the medium flows into the PFA tube. At $65{ }^{\circ} \mathrm{C}$, whatever the ethanol to oil molar ratio, the two liquids form an annular flow. Fig. 3 shows an annular flow obtained using a capillary tube ( $360 \mu \mathrm{m}$ OD, $180 \mu \mathrm{m}$ ID) inside a 1/16" PFA tube at $65{ }^{\circ} \mathrm{C}$. After $2 \mathrm{~min}$ of reaction time, the medium is homogeneous. At the end of the reaction $(16 \mathrm{~min})$, the medium also appears homogeneous although there are two phases in the microreactor (composed of very small droplets of glycerol in ester phase). This statement is confirmed as, after decantation in a collection vial, two phases are distinguishable. With constant flows, each tube length is related to a reaction time. We used a 2 m-length tube which corresponds approximately to a reaction time of $16 \mathrm{~min}$ (with a total flow rate $Q_{\text {tot }}=1.5 \mathrm{~mL} / \mathrm{h}$, which corresponds to a global speed $U_{\text {tot }}=2.12 \mathrm{~mm} / \mathrm{s}$ ). The tube was cut successively in order to obtain lower reaction times. Samples were collected during 15 min with a concomitant addition of a continuous $\mathrm{HCl}$ flow (3.7\% solution in water) in order to quench the reaction by neutralizing the alkali catalyst.

For each sample, the medium composition at different reaction times was determined by using gas chromatography coupled to a flame ionization detector (GC-FID) (Perkin Elmer Instrument, USA). Separation was carried out with a silica capillary column (CP-Sil 8 CB lowbleed/MS, 5\% phenyl+95\% dimethylpolysiloxane, $15 \mathrm{~m}, 0.32 \mathrm{~mm}$, $0.25 \mu \mathrm{m}$ ) from Varian (USA). The chromatograph was equipped with

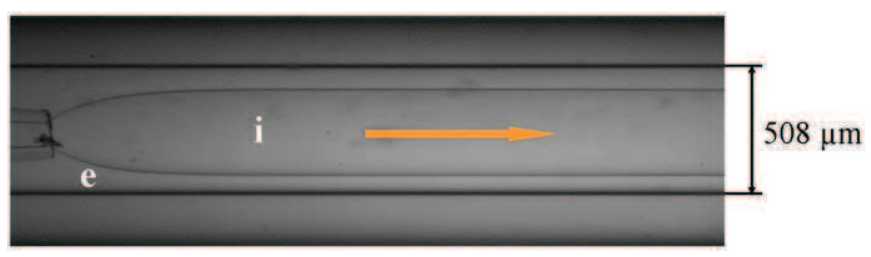

Fig. 3. Picture of the annular flow in a PFA tube where (i) is the internal fluid (sunflower oil) and (e) the external fluid (EtONa/EtOH solution). an automatic injector and the injections $(1 \mu \mathrm{L})$ were performed with an "on-column" injector. Ester and glycerol phases were not separated because the amount collected for analysis was about $0.3 \mathrm{~g}$, which was not enough to enable a reliable and reproducible separation. The entire samples were silylated with a mixture of MSHFBA and MI before analysis. The hydroxyl group silylation is intended to increase volatility and stability of the hydroxy compounds injected, and therefore to improve their detection. Cyclohexane was used as solvent to prepare standard solutions and heptadecane was used as internal standard. With this analytical procedure, molar concentrations of ethyl ester, oleic acid, monoglycerides, diglycerides and triglycerides were determined in the different phases resulting from the reaction. The gas chromatography data was used to calculate the total ethyl ester (more precisely ethyl oleate) content in oleic chains mixture as defined in Eq. (1):

Ethyl Ester Content $(\%)=\frac{[\mathrm{EE}]_{t}}{[\mathrm{EE}]_{t}+\left[\mathrm{C}_{18: 1}\right]_{t}+[\mathrm{MG}]_{t}+2 \times[\mathrm{DG}]_{t}+3 \times[\mathrm{TG}]_{t}}$

where $[\mathrm{EE}]_{t},\left[\mathrm{C}_{18: 1}\right]_{t},[\mathrm{MG}]_{t},[\mathrm{DG}]_{t}$ and $[\mathrm{TG}]_{t}$ represent, respectively the molar concentrations $(\mu \mathrm{mol} / \mathrm{mL})$ of ethyl oleate, oleic acid, oleic monoglycerides, diglycerides and triglycerides at a given time $t$.

\subsection{Results and discussion}

Different ethanol to oil molar ratios from 6.0 to 45.4 were tested in microreactors. The total ethyl ester contents obtained by GC-FID according to the reaction time are illustrated in Fig. 4. Whatever the ethanol to oil molar ratio, the reaction is quite fast as chemical equilibrium is reached after about $7 \mathrm{~min}$. According to Fig. 4, it is noticeable that the highest molar ratios (from 16.2 to 45.4) accelerate the initial kinetics of the reaction. This phenomenon can be explained by containment in microreactors: a higher ethanol to oil molar ratio generates an increase of the surface/ volume $(\mathrm{S} / \mathrm{V})$ ratio. Indeed, with stable annular flows (as we can see on Fig. 3), the $S / V$ ratio can be defined by the following Eq. (2):

$a=\frac{S}{V}=\frac{2 \times \pi \times r_{\mathrm{oil}} \times L}{\pi \times r_{\mathrm{oil}}^{2} \times L}=\frac{2}{r_{\mathrm{oil}}}$

where $a$ is the interfacial surface $\left(\mathrm{m}^{2} / \mathrm{m}^{3}\right), r_{\text {oil }}$ the radius of oil phase inside the tube $(m)$ and $L$ the length $(m)$. Thus, an increase of ethanol to oil molar ratio involves that $r_{\text {oil }}$ decreases and $\mathrm{S} / \mathrm{V}$ increases. Moreover, a radial gradient of oil concentration in the

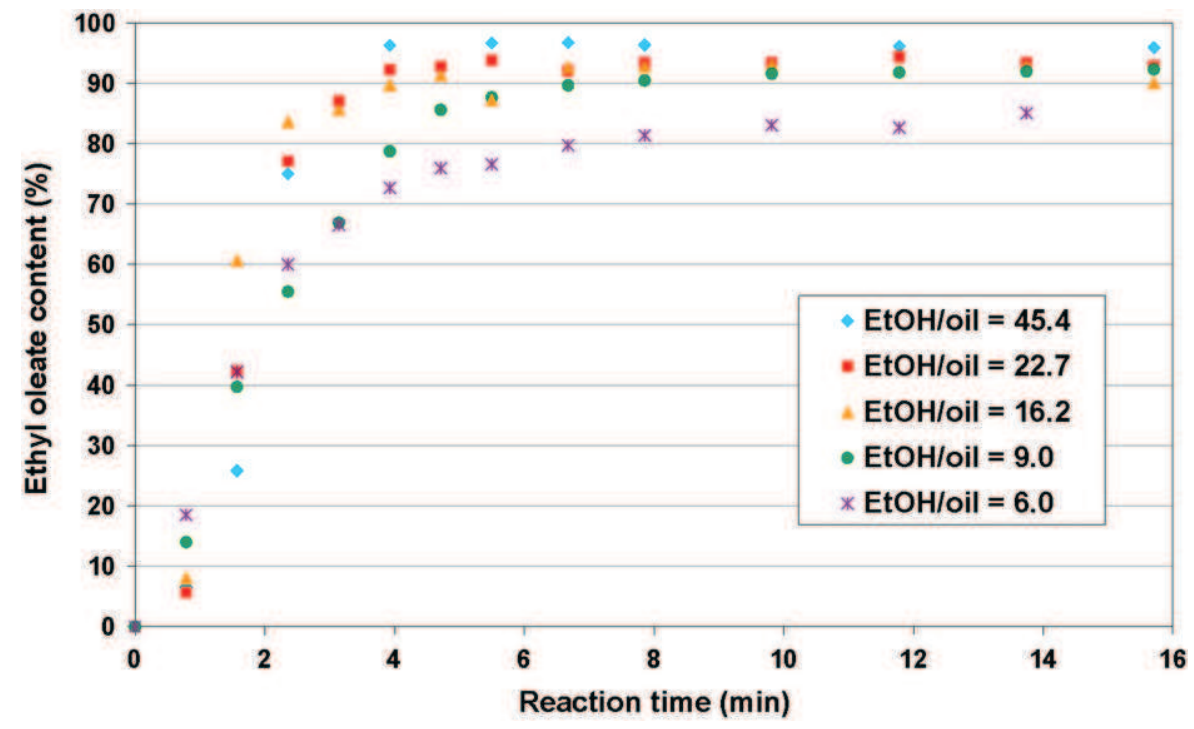

Fig. 4. Ethyl ester content in the reaction mixtures at $65^{\circ} \mathrm{C}$ according to the reaction time for various ethanol to oil molar ratios in microreactors. 
reactive ethanol phase appears for higher molar ratios. If the ethanol phase is more abundant, the oil concentration in this phase is initially weaker, generating a more important mass transfer of oil. These two phenomena induce better mass and heat fluxes, and consequently higher reactivity.

Besides, inflection points can be distinguishable between 0 and $2 \mathrm{~min}$, in particular for the molar ratios from 16.2 to 45.4 . The reaction may be controlled by mass transfer at the beginning and then by the chemical kinetics for reaction time higher than 2 min. Thus, thanks to these particular data gathered at very weak characteristic times, a mathematical model able to represent the behavior of the reaction medium (evolution of the various compounds as a function of reaction time) for various ethanol to oil molar ratios has been built.

\section{Modelling the kinetics}

\subsection{Hypotheses and resulting equations}

To build a model able to represent the chemical kinetics and the mass transfer phenomena, several hypotheses were formulated. They are described and discussed just below:

i. first order for all compounds as results obtained for 1st and 2nd order are not significantly different (Richard et al., 2011);

ii. biphasic medium constituted by two phases (annular flows) such as an oil phase (index $O$ ) and an ethanol phase (index ${ }_{E}$ ): we suppose the transfer of oil (TG) as well as reaction intermediates (DG and MG) from the oil phase towards the ethanol phase (Poljanšek and Likozar, 2011);

iii. reaction in ethanol phase: the homogeneous catalyst being soluble in ethanol phase, the reaction takes place in this phase after the transfer of the species from oil phase to ethanol phase. The reaction kinetics is accelerated for a high amount of catalyst, which involves a faster conversion of triglycerides and thus an increase of their transfer rate (Stamenković et al., 2011);

iv. first order for the catalyst soluble in ethanol phase. As long as the reaction occurs, ethanol disappears since it is consumed (reactant). As a result, the catalyst concentration increases during the reaction due to its regeneration;

v. balanced reactions: as the reactions are not total, TG, DG and MG are present at chemical equilibrium. Moreover, the quantity of TG tending towards 0 , the reversible rate constant of the first reaction $k_{-1}$ will be very low compared to the other rate constants;

vi. no secondary reactions with free fatty acids (such as oleic acid): to simplify the model, we considered that reactions of salification of fatty acids and saponification of triglycerides and esters in presence of water are very fast and therefore insignificant compared to the others;

vii. as a consequence of hypothesis (vi), a pseudo-component was created: EE concentration is the sum of ethyl oleate and oleic acid concentrations.

Thanks to all these hypotheses, following equations of the model Eqs. (3)-(11) represent mass transfer and 1st order reaction kinetics for all the compounds:

$$
\begin{aligned}
\frac{d[\mathrm{TG}]_{E}}{d t}= & -k_{1}[\mathrm{TG}]_{E}[\mathrm{EtOH}][\mathrm{Cata}]+k_{-1}[\mathrm{DG}]_{E}[\mathrm{EE}][\mathrm{Cata}] \\
& +k_{L} a_{(\mathrm{TG})}\left([\mathrm{TG}]_{O}-[\mathrm{TG}]_{E}\right) \\
\frac{d[\mathrm{TG}]_{O}}{d t}= & -k_{L} a_{(\mathrm{TG})}\left([\mathrm{TG}]_{O}-[\mathrm{TG}]_{E}\right)
\end{aligned}
$$

$$
\begin{aligned}
\frac{d[\mathrm{DG}]_{E}}{d t}= & k_{1}[\mathrm{TG}]_{E}[\mathrm{EtOH}][\mathrm{Cata}]-k_{-1}[\mathrm{DG}]_{E}[\mathrm{EE}][\mathrm{Cata}] \\
& -k_{2}[\mathrm{DG}]_{E}[\mathrm{EtOH}][\mathrm{Cata}]+k_{-2}[\mathrm{MG}]_{E}[\mathrm{EE}][\mathrm{Cata}] \\
& +k_{L} a_{(\mathrm{DG})}\left([\mathrm{DG}]_{O}-[\mathrm{DG}]_{E}\right)
\end{aligned}
$$

$\frac{d[\mathrm{DG}]_{O}}{d t}=-k_{L} a_{(\mathrm{DG})}\left([\mathrm{DG}]_{O}-[\mathrm{DG}]_{E}\right)$

$$
\begin{aligned}
\frac{d[\mathrm{MG}]_{E}}{d t}= & k_{2}[\mathrm{DG}]_{E}[\mathrm{EtOH}][\mathrm{Cata}]-k_{-2}[\mathrm{MG}]_{E}[\mathrm{EE}][\mathrm{Cata}] \\
& -k_{3}[\mathrm{MG}]_{E}[\mathrm{EtOH}][\mathrm{Cata}]+k_{-3}[\mathrm{G}][\mathrm{EE}][\mathrm{Cata}] \\
& +k_{\mathrm{L}} a_{(\mathrm{MG})}\left([\mathrm{MG}]_{O}-[\mathrm{MG}]_{E}\right)
\end{aligned}
$$

$\frac{d[\mathrm{MG}]_{O}}{d t}=-k_{\mathrm{L}} a_{(\mathrm{MG})}\left([\mathrm{MG}]_{O}-[\mathrm{MG}]_{E}\right)$

$\frac{d[G]}{d t}=k_{3}[\mathrm{MG}]_{E}[\mathrm{EtOH}][\mathrm{Cata}]-k_{-3}[\mathrm{G}][\mathrm{EE}][$ Cata $]$

$$
\begin{aligned}
\frac{d[\mathrm{EtOH}]}{d t}= & -k_{1}[\mathrm{TG}]_{E}[\mathrm{EtOH}][\mathrm{Cata}]+k_{-1}[\mathrm{DG}]_{E}[\mathrm{EE}][\mathrm{Cata}] \\
& -k_{2}[\mathrm{DG}]_{E}[\mathrm{EtOH}][\mathrm{Cata}]+k_{-2}[\mathrm{MG}]_{E}[\mathrm{EE}][\mathrm{Cata}] \\
& -k_{3}[\mathrm{MG}]_{E}[\mathrm{EtOH}][\mathrm{Cata}]+k_{-3}[\mathrm{G}][\mathrm{EE}][\text { Cata }]
\end{aligned}
$$

$$
\begin{aligned}
\frac{d[\mathrm{EE}]}{d t}= & k_{1}[\mathrm{TG}]_{E}[\mathrm{EtOH}][\mathrm{Cata}]-k_{-1}[\mathrm{DG}]_{E}[\mathrm{EE}][\mathrm{Cata}] \\
& +k_{2}[\mathrm{DG}]_{E}[\mathrm{EtOH}][\mathrm{Cata}]-k_{-2}[\mathrm{MG}]_{E}[\mathrm{EE}][\mathrm{Cata}] \\
& -k_{3}[\mathrm{MG}]_{E}[\mathrm{EtOH}][\mathrm{Cata}]-k_{-3}[\mathrm{G}][\mathrm{EE}][\mathrm{Cata}]
\end{aligned}
$$

The model was solved using a first order discretization. One second step time was chosen as it presents a good compromise between calculation time and numerical errors (a sensitivity analysis of the model was carried out for one experiment: ethanol to oil molar ratio 9.0 in $1 / 16^{\prime \prime}$ tubes).

\subsection{Determination of theoretical interfacial area}

In order to solve these latter equations, the interfacial area is needed. Eq. (2) gives this parameter as a function of oil radius, which can be determined with the speed profile inside the microreactor. It is considered as an annular flow (Fig. 3) at $65{ }^{\circ} \mathrm{C}$ and each flow verifies the Stokes equation presented in Eq. (12): $\eta \Delta u=\nabla P$

where $\eta$ is the viscosity (Pa s), $u$ the speed $(\mathrm{m} / \mathrm{s}$ ) and $P$ the pressure $(\mathrm{Pa})$. The speed profile of a steady and incompressible flow of Newtonian fluid in a microchannel with a radius of $254 \mu \mathrm{m}$ can be written as:

$u_{i}(r)=\frac{1}{4 \eta_{i}}\left(r^{2}-r_{i}^{2}\right) \partial_{z} P+\frac{1}{4 \eta_{e}}\left(r_{i}^{2}-R^{2}\right) \partial_{z} P \quad$ for $0<r<r_{i}$

$u_{e}(r)=\frac{1}{4 \eta_{e}}\left(r^{2}-R^{2}\right) \partial_{z} P \quad$ for $r_{i}<r<R$

where $u_{i}$ and $u_{e}$ are, respectively the speeds of internal and external fluids (Fig. 3) (m/s), $R$ the radius of the microchannel, $\eta_{l}$ and $\eta_{e}$, respectively the viscosities of internal and external fluids (Pa s) and $r_{i}$ the radius of oil $(\mu \mathrm{m})$. The flows $Q_{i}$ and $Q_{e}\left(\mathrm{~m}^{3} / \mathrm{s}\right)$ of the two fluids can be determined by integrating the speed profile on the section of the microchannel (Eqs. (15) and (16)).

$Q_{i}=-\frac{\pi r_{i}^{2}}{4}\left(\frac{r_{i}^{2}}{2 \eta_{i}}+\frac{R^{2}-r_{i}^{2}}{\eta_{i}}\right) \partial_{z} P$ for $0<r<r_{i}$

$Q_{e}=-\frac{\pi}{8 \eta_{e}}\left(R^{2}-r_{i}^{2}\right)^{2} \partial_{z} P \quad$ for $r_{i}<r<R$

For each set of flows (i.e., for each ethanol to oil molar ratio), Eqs. (15) and (16) can be solved and thus interfacial area (a) can 
be calculated with internal radius $\left(r_{i}\right)$ (Table 1 ). The highest ethanol to oil molar ratios are related to lower internal radius. This result is logical as $r_{i}$ represents the radius of internal fluid which is oil, and the oil volume is lower when the ethanol to oil molar ratio increases. From Table 1, the interfacial area clearly varies from one molar ratio to another. Indeed, for example, between a ratio 6.0 and 45.4, the interfacial area increases from 8365 to $9387 \mathrm{~m}^{2} / \mathrm{m}^{3}$, which represents a variation of $10.9 \%$.

\subsection{Determination of a set of parameters for each molar ratio}

After emitting hypotheses on several parameters and calculating notably the interfacial areas, it is possible to carry out identification of parameters on kinetic constants and mass transfer coefficients. Criterion minimization was used for identifying these kinetic parameters. The criterion is defined by the sum of the relative squared differences between the experimental measured data and the model output for each component of the reaction mixture (TG, DG, MG and $\mathrm{EE}$ ) at different reaction times:

Minimizationcriterion $=\sum_{j} \sum_{i}\left(\frac{C_{j}(i)_{\bmod }-C_{j}(i)_{\exp }}{C_{j}(i)_{\exp }}\right)^{2}$

where $C_{j}(i)_{\text {mod }}$ is the calculated concentration of component $j$ at reaction time $i, C_{j}(i)_{\exp }$ is the experimental concentration (GC-FID data) of component $j$ at reaction time $i$ with $j=\mathrm{TG}, \mathrm{DG}, \mathrm{MG}, \mathrm{EE}$ and $i=47,94,141,189,236,283,330,401,471,589,707,825,942 \mathrm{~s}$.

Table 1

Resulting oil radius in microchannel and interfacial area for various ethanol to oil molar ratios at $65^{\circ} \mathrm{C}$.

\begin{tabular}{clllll}
\hline Molar ratio $^{\mathrm{a}}$ & $\boldsymbol{Q}_{\boldsymbol{i}}(\mathbf{m L} / \mathbf{h})$ & $\boldsymbol{Q}_{\boldsymbol{e}}(\mathbf{m L} / \mathbf{h})$ & $\boldsymbol{Q}_{\text {tot }}{ }^{\mathrm{b}}(\mathbf{m L} / \mathbf{h})$ & $\boldsymbol{r}_{\boldsymbol{i}}(\mu \mathbf{m})$ & $\boldsymbol{a}\left(\mathbf{m}^{\mathbf{2}} / \mathbf{m}^{\mathbf{3}}\right)$ \\
\hline 6.0 & 1.090 & 0.410 & 1.500 & $\mathbf{2 3 9 . 1}$ & $\mathbf{8 3 6 5}$ \\
9.0 & 0.967 & 0.533 & 1.500 & $\mathbf{2 3 5 . 9}$ & $\mathbf{8 4 7 9}$ \\
16.2 & 0.755 & 0.745 & 1.500 & $\mathbf{2 2 9 . 6}$ & $\mathbf{8 7 1 0}$ \\
22.7 & 0.630 & 0.870 & 1.500 & $\mathbf{2 2 5 . 1}$ & $\mathbf{8 8 8 6}$ \\
45.4 & 0.400 & 1.100 & 1.500 & $\mathbf{2 1 3 . 1}$ & $\mathbf{9 3 8 7}$ \\
\hline
\end{tabular}

a For all molar ratios, the amount of catalyst is constant ( $1 \mathrm{wt} \%$ compared to oil mass).

${ }^{\mathrm{b}}$ With $Q_{\mathrm{tot}}=Q_{i}+Q_{e}$
The criterion chosen to work with is based on the squared sums of relative variations and not on the squared sums of absolute variations because some concentrations such as those of TG, DG and MG are much lower than the EE concentrations. Low differences in concentrations of TG, DG and MG between the experimental data and the modelling data would generate very important variations by comparison with errors on EE. Thus, working with a criterion on relative variations, errors on all compounds are balanced, which is more representative of the system.

The minimization criterion on the relative squared variations was carried out separately for each molar ratio by using the kinetic constants and the mass transfer coefficients as variable parameters. The corresponding curves are represented on Fig. 5. It should be pointed out that the model enables the representation of also the evolution of glycerol concentration as a function of reaction time, in addition to the concentration of the other components. The results of the parameters identification for the ethanol to oil molar ratio of 6.0 are gathered in Table 2. Results for the molar ratio 6.0 are satisfactory visually and numerically since the model curves really fit the experimental data for all the components and the total sum of their relative variations $\left(\Sigma \Sigma_{(j)}\right)$ for all reaction times is low (equal to 5 ). Kinetics constants are all of the same order of magnitude (between 1 and $10^{-2} \mathrm{~L}^{2} / \mathrm{mol}^{2} / \mathrm{s}$ ) except $k_{-1}$ which is very low (about $10^{-10} \mathrm{~L}^{2} / \mathrm{mol}^{2} / \mathrm{s}$ ). This confirms hypothesis $(v)$ : the first reaction of the chemical scheme (Fig. 1) is nearly total whereas the two other steps are balanced reactions.

Parameters identification has been lead separately for each ethanol to oil molar ratio and results are also given in Table 2 . Although $\Sigma_{(\mathrm{TG})}$ are quite high for ethanol to oil molar ratios 16.2 and 22.7, concentrations tendencies are correctly represented. Indeed, as concentrations of TG are very low, small variations can generate high relative errors.

\subsection{Determination of a global set of parameters}

After determining the kinetic parameters (kinetics constants and mass transfer coefficients) for each ethanol to oil molar ratio, we chose to establish common parameters able to correctly represent all the molar ratios used. First of all, the system was optimized using different initialization parameters and particularly the values

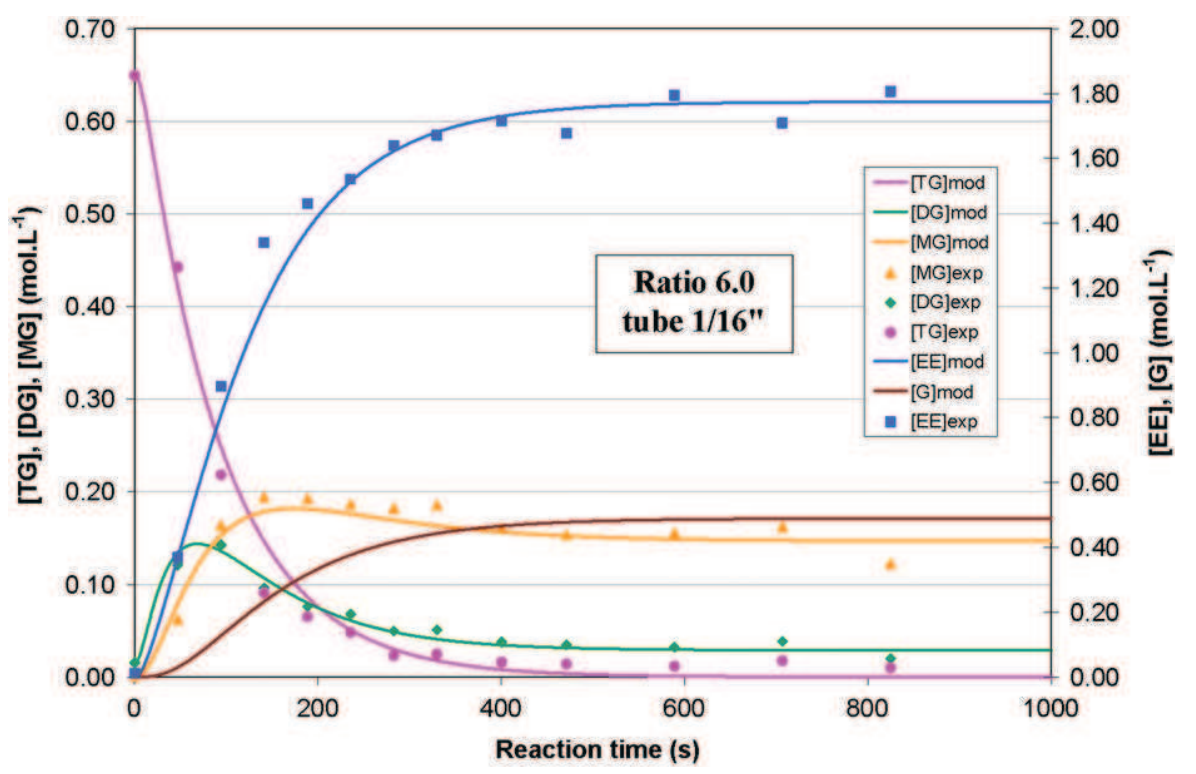

Fig. 5. Evolution of the concentrations of the various oleic compounds according to the reaction time for a molar ratio of 6.0 (continuous lines are used for the model and singular points for the experimental data). 
Table 2

Results of the parameters identification carried out on 9 parameters by minimizing separately the criterion of the relative squared variations for each ethanol to oil molar ratio.

\begin{tabular}{|c|c|c|c|c|c|}
\hline Parameters & 6.0 & 9.0 & 16.2 & 22.7 & 45,4 \\
\hline \multicolumn{6}{|c|}{ Kinetics constants } \\
\hline$k_{1}\left(\mathrm{~L}^{2} / \mathrm{mol}^{2} \mathrm{~s}\right)$ & $2.45 \times 10^{-1}$ & $1.00 \times 10^{-1}$ & $1.00 \times 10^{-1}$ & $1.45 \times 10^{-1}$ & $1.45 \times 10^{-1}$ \\
\hline$k_{-1}\left(\mathrm{~L}^{2} / \mathrm{mol}^{2} \mathrm{~s}\right)$ & $8.65 \times 10^{-11}$ & $8.65 \times 10^{-11}$ & $8.65 \times 10^{-11}$ & $8.65 \times 10^{-11}$ & $8.65 \times 10^{-11}$ \\
\hline$k_{2}\left(\mathrm{~L}^{2} / \mathrm{mol}^{2} \mathrm{~s}\right)$ & $1.22 \times 10^{-1}$ & $1.09 \times 10^{-1}$ & $1.70 \times 10^{-1}$ & $2.00 \times 10^{-1}$ & $2.00 \times 10^{-1}$ \\
\hline$k_{-2}\left(\mathrm{~L}^{2} / \mathrm{mol}^{2} \mathrm{~s}\right)$ & $3.75 \times 10^{-2}$ & $1.23 \times 10^{-2}$ & $2.45 \times 10^{-2}$ & $3.75 \times 10^{-2}$ & $3.75 \times 10^{-2}$ \\
\hline$k_{3}\left(\mathrm{~L}^{2} / \mathrm{mol}^{2} \mathrm{~s}\right)$ & $5.37 \times 10^{-2}$ & $4.50 \times 10^{-2}$ & $5.37 \times 10^{-2}$ & $8.00 \times 10^{-2}$ & $8.00 \times 10^{-2}$ \\
\hline $\begin{array}{l}k_{-3}\left(\mathrm{~L}^{2} / \mathrm{mol}^{2} \mathrm{~s}\right) \\
\text { Mass transfer co }\end{array}$ & $1.26 \times 10^{-2}$ & $9.21 \times 10^{-3}$ & $1.26 \times 10^{-2}$ & $3.00 \times 10^{-2}$ & $3.00 \times 10^{-2}$ \\
\hline$k_{L(\mathrm{TG})}(\mathrm{m} / \mathrm{s})$ & $1.50 \times 10^{-6}$ & $1.82 \times 10^{-6}$ & $2.00 \times 10^{-6}$ & $1.00 \times 10^{-6}$ & $1.00 \times 10^{-6}$ \\
\hline$k_{L(\mathrm{DG})}(\mathrm{m} / \mathrm{s})$ & $1.76 \times 10^{-5}$ & $1.92 \times 10^{-5}$ & $4.69 \times 10^{-6}$ & $1.76 \times 10^{-5}$ & $1.76 \times 10^{-5}$ \\
\hline $\begin{array}{l}k_{L(\mathrm{MG})}(\mathrm{m} / \mathrm{s}) \\
\text { Relative squared }\end{array}$ & $1.54 \times 10^{-6}$ & $6.33 \times 10^{-7}$ & $1.75 \times 10^{-5}$ & $1.54 \times 10^{-6}$ & $1.54 \times 10^{-6}$ \\
\hline$\Sigma_{(\mathrm{EE})}$ & 0.04 & 0.01 & 1.64 & 2.50 & 1.24 \\
\hline$\Sigma_{(\mathrm{MG})}$ & 0.16 & 0.51 & 50.20 & 8.21 & 6.52 \\
\hline$\Sigma_{(\mathrm{DG})}$ & 0.36 & 1.17 & 6.17 & 11.13 & 0.48 \\
\hline$\Sigma_{(\mathrm{TG})}$ & 4.29 & 7.22 & 373.28 & 714.68 & 6.11 \\
\hline$\Sigma \Sigma_{(j)}$ & 5 & 9 & 431 & 737 & 14 \\
\hline
\end{tabular}

Table 3

Influence of parameters initialization on the results for a global optimisation (for the five ethanol to oil molar ratios).

\begin{tabular}{|c|c|c|c|c|c|}
\hline \multirow[t]{2}{*}{ Parameters } & \multicolumn{5}{|c|}{ Initialization with values of each molar ratio } \\
\hline & 6.0 & 9.0 & 16.2 & 22.7 & 45.4 \\
\hline$k_{1}\left(\mathrm{~mol}^{-2} \mathrm{~L}^{2} \mathrm{~s}^{-1}\right)$ & $1.04 \times 10^{-1}$ & $1.12 \times 10^{-1}$ & $1.06 \times 10^{-1}$ & $1.10 \times 10^{-1}$ & $1.10 \times 10^{-1}$ \\
\hline$k_{-1}\left(\mathrm{~mol}^{-2} \mathrm{~L}^{2} \mathrm{~s}^{-1}\right)$ & $8.65 \times 10^{-11}$ & $8.65 \times 10^{-11}$ & $3.80 \times 10^{-12}$ & $8.65 \times 10^{-11}$ & $8.65 \times 10^{-11}$ \\
\hline$k_{2}\left(\mathrm{~mol}^{-2} \mathrm{~L}^{2} \mathrm{~s}^{-1}\right)$ & $1.53 \times 10^{-1}$ & $1.59 \times 10^{-1}$ & $1.58 \times 10^{-1}$ & $2.03 \times 10^{-1}$ & $2.03 \times 10^{-1}$ \\
\hline$k_{-2}\left(\mathrm{~mol}^{-2} \mathrm{~L}^{2} \mathrm{~s}^{-1}\right)$ & $2.53 \times 10^{-10}$ & $1.84 \times 10^{-2}$ & $1.85 \times 10^{-2}$ & $1.15 \times 10^{0}$ & $1.15 \times 10^{0}$ \\
\hline$k_{3}\left(\mathrm{~mol}^{-2} \mathrm{~L}^{2} \mathrm{~s}^{-1}\right)$ & $6.85 \times 10^{-1}$ & $6.64 \times 10^{-1}$ & $4.70 \times 10^{-1}$ & $2.88 \times 10^{-1}$ & $2.88 \times 10^{-1}$ \\
\hline$k_{-3}\left(\mathrm{~mol}^{-2} \mathrm{~L}^{2} \mathrm{~s}^{-1}\right)$ & $2.17 \times 10^{-1}$ & $2.17 \times 10^{-1}$ & $1.54 \times 10^{-1}$ & 0.000 & 0.000 \\
\hline$k_{L(T G)}(\mathrm{m} / \mathrm{s})$ & $3.83 \times 10^{-6}$ & $3.55 \times 10^{-6}$ & $3.79 \times 10^{-6}$ & $3.62 \times 10^{-6}$ & $3.62 \times 10^{-6}$ \\
\hline$k_{L(D G)}(\mathrm{m} / \mathrm{s})$ & $1.00 \times 10^{-4}$ & $1.00 \times 10^{-4}$ & $1.00 \times 10^{-4}$ & $3.53 \times 10^{-5}$ & $3.53 \times 10^{-5}$ \\
\hline$k_{L(M G)}(\mathrm{m} / \mathrm{s})$ & $5.23 \times 10^{-6}$ & $4.42 \times 10^{-6}$ & $2.02 \times 10^{-6}$ & $5.29 \times 10^{-7}$ & $5.29 \times 10^{-7}$ \\
\hline$\Sigma \Sigma_{(\text {ratio 6.0) }}$ & 15.69 & 11.25 & 11.16 & 20.36 & 20.36 \\
\hline$\Sigma \Sigma_{\text {(ratio 9.0) }}$ & 12.77 & 9.07 & 9.01 & 17.05 & 17.05 \\
\hline$\Sigma \Sigma_{\text {(ratio } 16.2)}$ & 38.91 & 33.73 & 33.67 & 48.29 & 48.29 \\
\hline$\Sigma \Sigma_{\text {(ratio 22.7) }}$ & 37.27 & 34.80 & 35.23 & 46.77 & 46.77 \\
\hline$\Sigma \Sigma_{\text {(ratio } 45.4)}$ & 19.22 & 19.20 & 18.92 & 22.64 & 22.64 \\
\hline$\Sigma \Sigma \Sigma_{(\text {ratios })}$ & 124 & 108 & 108 & 155 & 155 \\
\hline
\end{tabular}

previously determined for each molar ratio. The criterion to be minimized is here the sum of the sums of the relative squared variations of each component at each reaction time for all molar ratios $\left(\Sigma \Sigma \Sigma_{(\text {ratios })}\right)$.

Depending on the initializing parameters (different sets of kinetic and mass transfer parameters established for each molar ratio), the resulting criterion and parameters can be different. We gathered the results showing the influence of initialization in the Table 3 . The final value of the minimization criterion $\left(\Sigma \Sigma \Sigma_{\text {(ratios) }}\right)$ varies between 108 and 155 depending on the initialization of the set of parameters, values which are mathematically acceptable. However, although the modelling curves correctly fit to the experimental concentrations for ethyl ester whatever the molar ratio used, the representation of other compounds are less acceptable.

Besides, we manually determined a set of parameters able to correctly represent the evolutions of all the components of all molar ratios used. To initialize this parameters identification, we analyzed results of Table 2 and averaged each parameter. Kinetic parameters are all approximately constant, except $k_{1}$ for the molar ratio 6.0 which is equal to twice the $k_{1}$ for other molar ratios. Thus, we did not consider it to calculate the constant average $k_{1}$. Concerning the mass transfer coefficients, $k_{L(\mathrm{DG})}$ and $k_{\mathrm{L}(\mathrm{MG})}$ for an ethanol to oil molar ratio of 16.2 are also different from others $k_{L}$ of other molar ratios (Table 2). These values, consequently, have not been used to calculate the average coefficient $k_{L}$. A global parameters identification minimizing criterion $\Sigma \Sigma \Sigma_{\text {(ratios) }}$ has been lead and the set of established parameters gives a criterion of 108 (Table 4). But these parameters do not allow to correctly represent the evolutions of all compounds, in particular evolutions of monoglycerides. That is why we also decided to play manually on the parameters in order to improve the representation of all the reaction compounds for all molar ratios. A set of parameters (kinetics constants and mass transfer coefficients) given in Table 4 is able to correctly represent evolutions of various compounds for each ethanol to oil molar ratio used. Even if the total sum of the sums of the relative squared variations is much higher (1165) than the previous value (only 108), it is essentially due to the high value of the sum of the relative squared variations for the molar ratio of 16.2 (945) which represents $81 \%$ of the total sum. This important sum can be explained primarily by the relative squared variations obtained on TG, which represents a maximum of $96 \%$ of the total sum for molar ratio 16.2 , because of the rapid progression of TG concentrations towards values close to zero. Thus, corresponding graphs to this set of parameters, satisfactory for the whole of molar ratios used, are presented on Fig. 6. For all molar ratios used, we can note that the reactions are limited by chemical kinetics. Thus, in order to validate the model which has just been presented, we decided to carry out a reaction where mass transfer would be more limiting. 
Table 4

Results of global parameters identification with criterion minimization (1) and manual parameters identification (2).

\begin{tabular}{|c|c|c|c|}
\hline Parameters & $\begin{array}{l}\text { Initialization } \\
\text { (averaging values of Table 2) }\end{array}$ & $\begin{array}{l}\text { (1) Global parameters } \\
\text { identification }\end{array}$ & $\begin{array}{l}\text { (2) Global manual } \\
\text { adjustement }\end{array}$ \\
\hline$k_{1}\left(\mathrm{~mol}^{-2} \mathrm{~L}^{2} \mathrm{~s}^{-1}\right)$ & $1.23 \times 10^{-1}$ & $1.03 \times 10^{-1}$ & $1.20 \times 10^{-1}$ \\
\hline$k_{-1}\left(\mathrm{~mol}^{-2} \mathrm{~L}^{2} \mathrm{~s}^{-1}\right)$ & $8.65 \times 10^{-11}$ & $8.82 \times 10^{-11}$ & $8.65 \times 10^{-11}$ \\
\hline$k_{2}\left(\mathrm{~mol}^{-2} \mathrm{~L}^{2} \mathrm{~s}^{-1}\right)$ & $1.60 \times 10^{-1}$ & $1.59 \times 10^{-1}$ & $1.50 \times 10^{-1}$ \\
\hline$k_{-2}\left(\mathrm{~mol}^{-2} \mathrm{~L}^{2} \mathrm{~s}^{-1}\right)$ & $2.98 \times 10^{-2}$ & $1.86 \times 10^{-2}$ & $3.00 \times 10^{-2}$ \\
\hline$k_{3}\left(\mathrm{~mol}^{-2} \mathrm{~L}^{2} \mathrm{~s}^{-1}\right)$ & $6.25 \times 10^{-2}$ & $5.42 \times 10^{-1}$ & $5.00 \times 10^{-2}$ \\
\hline$k_{-3}\left(\mathrm{~mol}^{-2} \mathrm{~L}^{2} \mathrm{~s}^{-1}\right)$ & $1.89 \times 10^{-2}$ & $1.77 \times 10^{-1}$ & $1.20 \times 10^{-2}$ \\
\hline$k_{L(T G)}(\mathrm{m} / \mathrm{s})$ & $1.47 \times 10^{-6}$ & $3.90 \times 10^{-6}$ & $1.50 \times 10^{-6}$ \\
\hline$k_{L(D G)}(\mathrm{m} / \mathrm{s})$ & $1.80 \times 10^{-5}$ & $1.24 \times 10^{-5}$ & $1.70 \times 10^{-5}$ \\
\hline$k_{L(M G)}(\mathrm{m} / \mathrm{s})$ & $1.31 \times 10^{-6}$ & $2.70 \times 10^{-6}$ & $1.50 \times 10^{-6}$ \\
\hline$\Sigma \Sigma_{\text {(ratio 6.0) }}$ & 8.11 & 11.08 & 7.48 \\
\hline$\Sigma \Sigma_{\text {(ratio 9.0) }}$ & 31.47 & 9.09 & 26.58 \\
\hline$\Sigma \Sigma_{(\text {ratio } 16.2)}$ & 1001.89 & 33.08 & 944.76 \\
\hline$\Sigma \Sigma_{(\text {ratio } 22.7)}$ & 163.95 & 35.54 & 160.96 \\
\hline$\Sigma \Sigma_{(\text {ratio } 45.4)}$ & 18.30 & 18.73 & 25.63 \\
\hline$\Sigma \Sigma \Sigma($ ratios $)$ & 1224 & 108 & 1165 \\
\hline
\end{tabular}
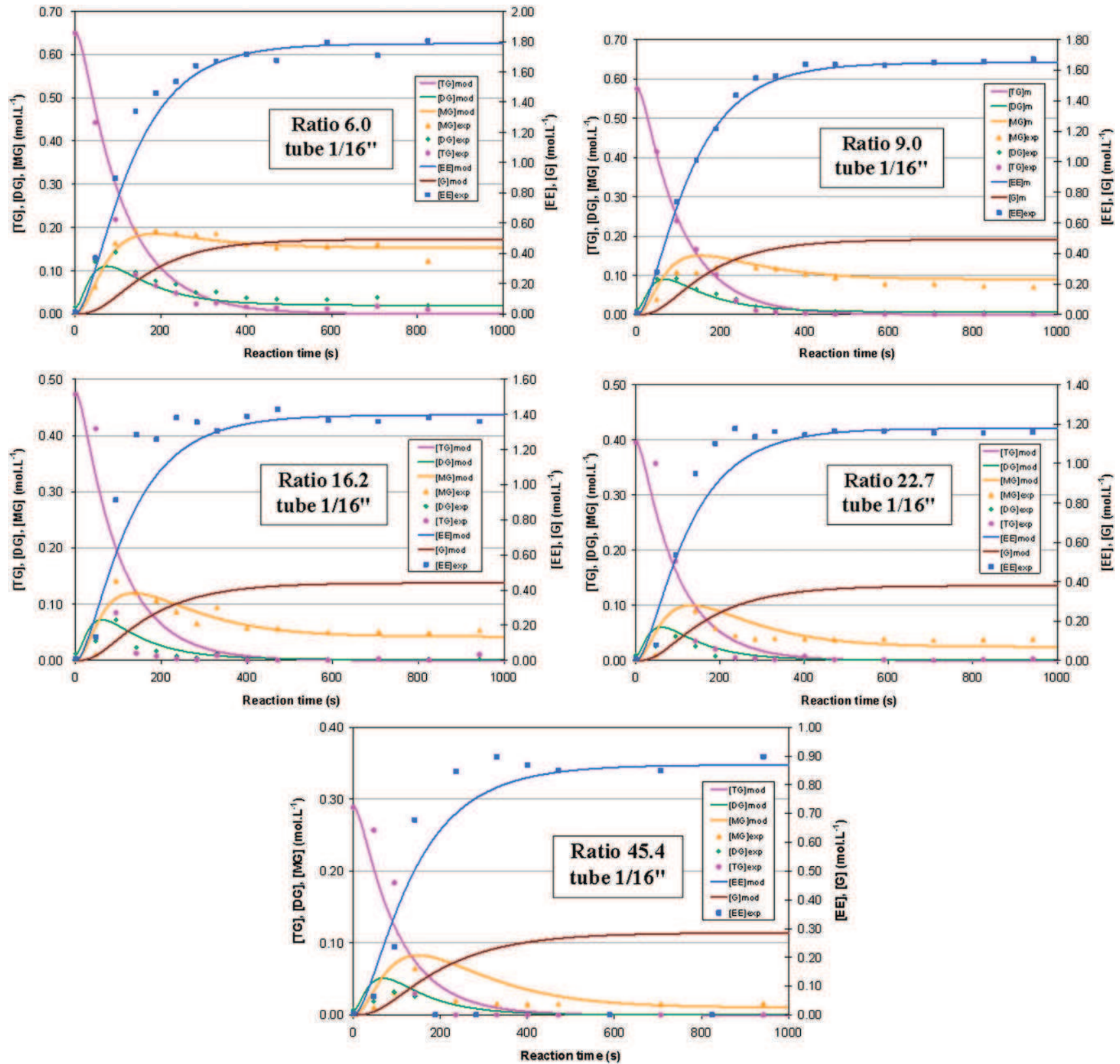

Fig. 6. Modelling and experimental data representing the evolution of reaction medium composition according to the reaction time with the same set of parameters manually determined (valid for all molar ratios). 


\subsection{Validation of the model with an experiment in millireactor}

To carry out a reaction with more mass transfer limitation, it is necessary to increase the working scale. We thus implemented the reaction in millireactor instead of microreactors. 1/16" PFA tubes ( $508 \mu \mathrm{m}$ as internal diameter) were substituted by PFA tubes with higher dimensions: 1/8" PFA tubes $(3.175 \mathrm{~mm}$ as external diameter and $2.362 \mathrm{~mm}$ as internal diameter). As we decided to work at the same speed as in microreactors $\left(U_{\text {tot }}=2.12 \mathrm{~mm} / \mathrm{s}\right.$ ), flow rates had to be increased $\left(Q_{t o t}=33.480 \mathrm{~mL} / \mathrm{h}\right)$. We chose to work with an ethanol to oil molar ratio of 9.0 with the same amount of catalyst (1 wt\% compared to oil mass) and the same temperature $\left(65^{\circ} \mathrm{C}\right)$ as in microreactors. The internal radius is $1096.6 \mu \mathrm{m}$ and the interfacial area in this millireactor is $1823.84 \mathrm{~m}^{2} / \mathrm{m}^{3}$ (i.e., 5 times lower in comparison with the interfacial area for the same ratio in microreactor (Table 1)), which generates a more important limitation due to mass transfer. The flow pattern in this millireactor was the same as the pattern described in the microreactor, i.e., an annular flow at the beginning of the reaction and then, the reaction medium appears to be homogeneous with probably very small droplets of glycerol in the ester phase at the end of the reaction.

When the parameter identification was carried out on all experiments ( $1 / 16^{\prime \prime}$ tubes and $1 / 8^{\prime \prime}$ tube) varying initialization, results were rather satisfactory numerically but not visually, in particular for components in low quantities in the reaction mixture. Indeed, the maximum MG concentration after a few minutes of reaction is not represented: MG concentration increases gradually until reaching a plateau (corresponding to the equilibrium of the third step of transesterification reaction), which does not correspond to the experimental reality
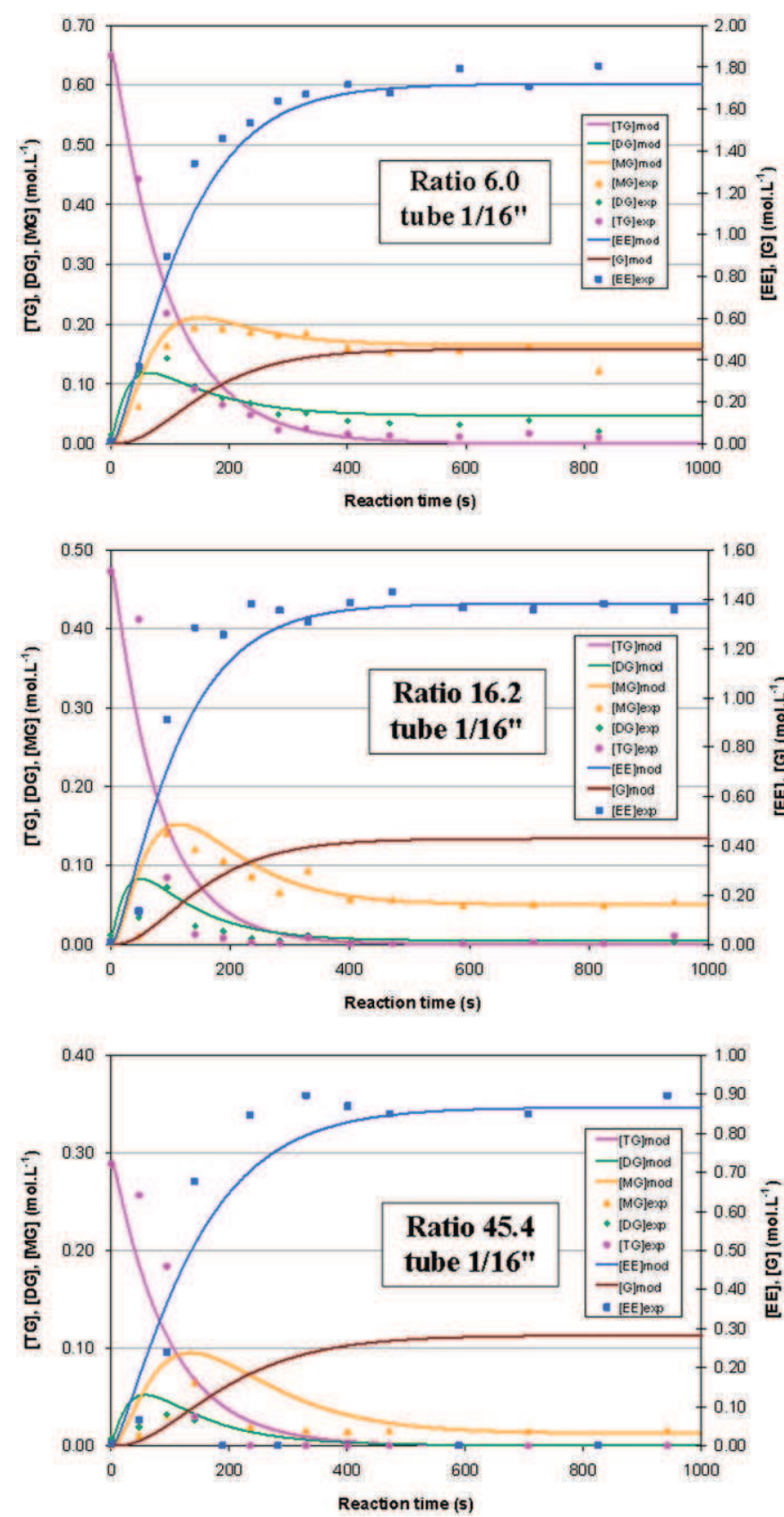
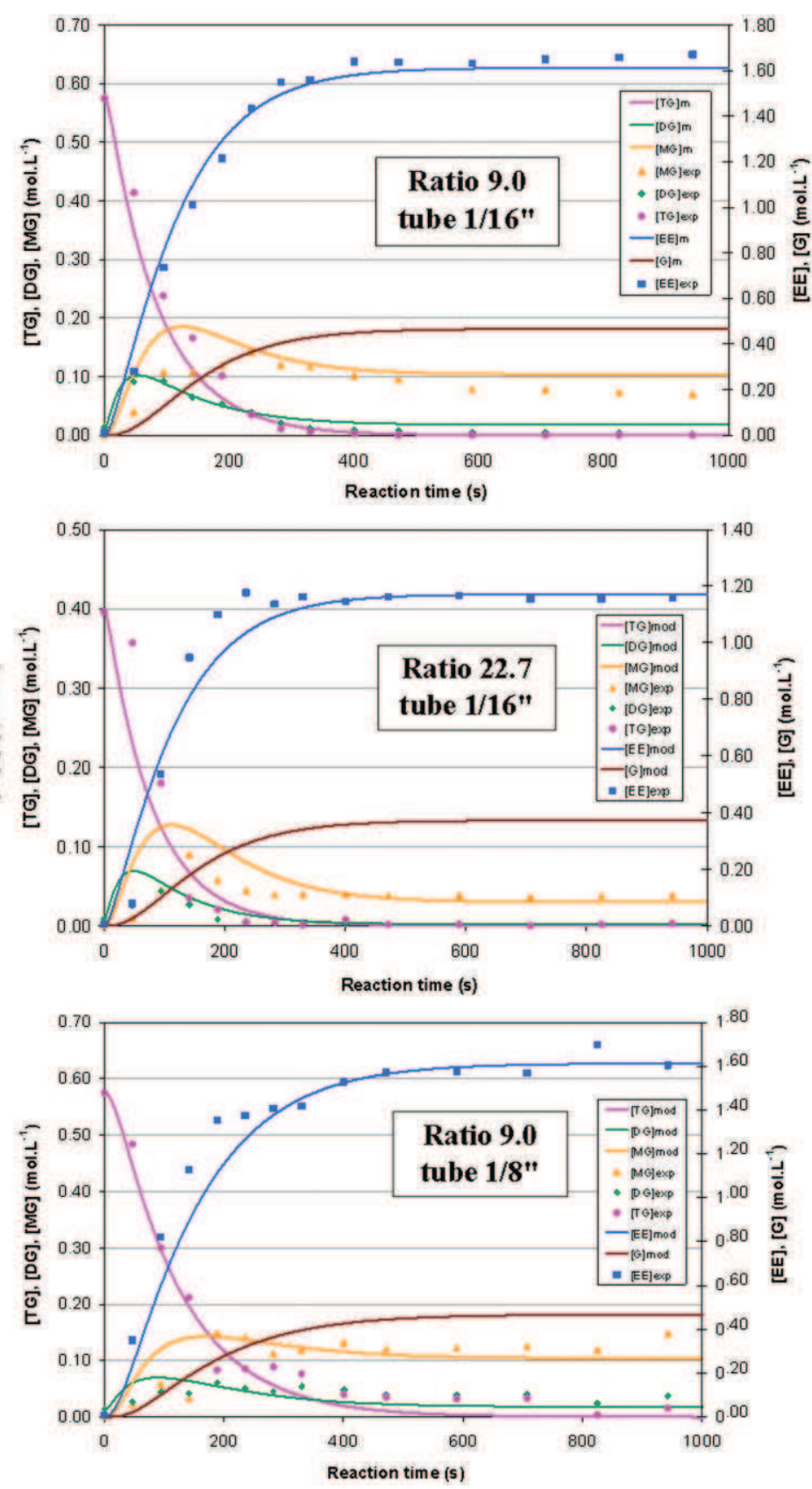

Fig. 7. Modelling and experimental data representing the evolution of various components according to reaction time with the same set of parameters (valid for all molar ratios and both tube sizes). 
Table 5

Validation of the model considering experiments in microreactor (limited by chemical kinetics) and millireactor (more limited by mass transfer).

\begin{tabular}{|c|c|c|c|}
\hline Parameters & $\begin{array}{l}\text { Numerical parameters identification } \\
\text { for the experiment in millireactor }\end{array}$ & $\begin{array}{l}\text { Manual parameters determination } \\
\text { for the experiment in millireactor }\end{array}$ & $\begin{array}{l}\text { Manual adjustement } \\
\text { for all experiments }\end{array}$ \\
\hline$k_{1}\left(\mathrm{~mol}^{-2} \mathrm{~L}^{2} \mathrm{~s}^{-1}\right)$ & $2.14 \times 10^{-1}$ & $1.00 \times 10^{-1}$ & $5.00 \times 10^{-2}$ \\
\hline$k_{-1}\left(\mathrm{~mol}^{-2} \mathrm{~L}^{2} \mathrm{~s}^{-1}\right)$ & $8.65 \times 10^{-11}$ & $8.65 \times 10^{-11}$ & $1.00 \times 10^{-10}$ \\
\hline$k_{2}\left(\mathrm{~mol}^{-2} \mathrm{~L}^{2} \mathrm{~s}^{-1}\right)$ & $2.49 \times 10^{-1}$ & $1.50 \times 10^{-1}$ & $1.50 \times 10^{-1}$ \\
\hline$k_{-2}\left(\mathrm{~mol}^{-2} \mathrm{~L}^{2} \mathrm{~s}^{-1}\right)$ & $1.48 \times 10^{-1}$ & $1.00 \times 10^{-1}$ & $7.00 \times 10^{-2}$ \\
\hline$k_{3}\left(\mathrm{~mol}^{-2} \mathrm{~L}^{2} \mathrm{~s}^{-1}\right)$ & $3.02 \times 10^{-1}$ & $5.00 \times 10^{-2}$ & $5.00 \times 10^{-2}$ \\
\hline$k_{-3}\left(\mathrm{~mol}^{-2} \mathrm{~L}^{2} \mathrm{~s}^{-1}\right)$ & $1.96 \times 10^{-1}$ & $2.00 \times 10^{-2}$ & $1.50 \times 10^{-2}$ \\
\hline$k_{L(T G)}(\mathrm{m} / \mathrm{s})$ & $3.96 \times 10^{-6}$ & $1.00 \times 10^{-5}$ & $1.00 \times 10^{-5}$ \\
\hline$k_{L(D G)}(\mathrm{m} / \mathrm{s})$ & $6.23 \times 10^{-6}$ & $1.00 \times 10^{-5}$ & $1.00 \times 10^{-5}$ \\
\hline$k_{L(M G)}(\mathrm{m} / \mathrm{s})$ & $9.42 \times 10^{-7}$ & $1.00 \times 10^{-5}$ & $1.00 \times 10^{-5}$ \\
\hline$\Sigma \Sigma_{\text {(ratio 6.0) }}\left(1 / 16^{\prime \prime}\right)$ & - & - & 8 \\
\hline$\Sigma \Sigma_{\text {(ratio 9.0) }}\left(1 / 16^{\prime \prime}\right)$ & - & - & 108 \\
\hline$\Sigma \Sigma_{(\text {ratio } 16.2)}\left(1 / 16^{\prime \prime}\right)$ & - & - & 348 \\
\hline$\Sigma \Sigma_{(\text {ratio } 22.7)}\left(1 / 16^{\prime \prime}\right)$ & - & - & 100 \\
\hline$\Sigma \Sigma_{(\text {ratio } 45.4)}\left(1 / 16^{\prime \prime}\right)$ & - & - & 34 \\
\hline$\Sigma \Sigma_{(\text {ratio } 9,0)}\left(1 / 8^{\prime \prime}\right)$ & 6 & 45 & 25 \\
\hline$\Sigma \Sigma \Sigma($ ratios $)$ & - & - & 623 \\
\hline
\end{tabular}

a "all experiments" means the 5 experiments in microreactor +1 experiment in millireactor

Table 6

Comparison of different mass transfer coefficients obtained from literature and from this work.

\begin{tabular}{lllll}
\hline Parameters & Stamenković et al., 2008 & Frascari et al., 2009 & Klofutar et al., 2010 & Our work \\
\hline Oil & Sunflower & Sunflower & Sunflower & Sunflower \\
Alcohol & Methanol & Methanol & Methanol & Ethanol \\
Catalyst type & $\mathrm{KOH}$ & $\mathrm{KOH}$ & $\mathrm{KOH}$ & $\mathrm{EtONa}$ \\
Catalyst amount & $1 \mathrm{wt} \%$ & $0.8 \mathrm{wt} \%$ & $1 \mathrm{wt} \%$ & $6 \mathrm{wt}^{\circ} \mathrm{C}$ \\
Temperature & $30{ }^{\circ} \mathrm{C}$ & $60{ }^{\circ} \mathrm{C}$ & 50 & - \\
Stirring & $200 \mathrm{rpm}$ & $200 \mathrm{rpm}$ & $500 \mathrm{rpm}$ & $1.00 \times 10^{-5}$ \\
$k_{L}(\mathrm{~m} / \mathrm{s})$ & $7.80 \times 10^{-5}$ & $1.40 \times 10^{-4}$ & $1.46-1.93 \times 10^{-7}$ & \\
\hline
\end{tabular}

Table 7

Comparison of different sets of kinetics parameters obtained from literature and from this work.

\begin{tabular}{|c|c|c|c|c|c|}
\hline Parameters & Noureddini and Zhu, 1997 & Vicente et al., 2005 & Bambase et al., 2007 & Klofutar et al., 2010 & Our work \\
\hline Oil & Soybean & Sunflower & Sunflower & Sunflower & Sunflower \\
\hline Alcohol & Methanol & Methanol & Methanol & Methanol & Ethanol \\
\hline Catalyst type & $\mathrm{NaOH}$ & $\mathrm{KOH}$ & $\mathrm{NaOH}$ & $\mathrm{KOH}$ & EtONa \\
\hline Catalyst amount & $0.2 \mathrm{wt} \%$ & $1 \mathrm{wt} \%$ & $1 \mathrm{wt} \%$ & $1 \mathrm{wt} \%$ & $1 \mathrm{wt} \%$ \\
\hline Temperature & $50^{\circ} \mathrm{C}$ & $65^{\circ} \mathrm{C}$ & $60{ }^{\circ} \mathrm{C}$ & $50{ }^{\circ} \mathrm{C}$ & $65^{\circ} \mathrm{C}$ \\
\hline Stirring & $300 \mathrm{rpm}$ & $600 \mathrm{rpm}$ & $400 \mathrm{rpm}$ & $500 \mathrm{rpm}$ & - \\
\hline$k_{1}\left(\mathrm{~mol}^{-2} \mathrm{~L}^{2} \mathrm{~s}^{-1}\right)$ & $8.33 \times 10^{-4}$ & $5.10 \times 10^{-2}$ & $3.86 \times 10^{-3}$ & $1.29 \times 10^{-3}$ & $5.00 \times 10^{-2}$ \\
\hline$k_{-1}\left(\mathrm{~mol}^{-2} \mathrm{~L}^{2} \mathrm{~s}^{-1}\right)$ & $1.83 \times 10^{-3}$ & $3.98 \times 10^{-1}$ & $2.77 \times 10^{-4}$ & $4.42 \times 10^{-4}$ & $1.00 \times 10^{-10}$ \\
\hline$k_{2}\left(\mathrm{~mol}^{-2} \mathrm{~L}^{2} \mathrm{~s}^{-1}\right)$ & $3.58 \times 10^{-3}$ & $5.42 \times 10^{-1}$ & $7.48 \times 10^{-3}$ & $2.80 \times 10^{-3}$ & $1.50 \times 10^{-1}$ \\
\hline$k_{-2}\left(\mathrm{~mol}^{-2} \mathrm{~L}^{2} \mathrm{~s}^{-1}\right)$ & $2.05 \times 10^{-2}$ & $9.58 \times 10^{-1}$ & $1.78 \times 10^{-3}$ & $1.12 \times 10^{-3}$ & $7.00 \times 10^{-2}$ \\
\hline$k_{3}\left(\mathrm{~mol}^{-2} \mathrm{~L}^{2} \mathrm{~s}^{-1}\right)$ & $4.03 \times 10^{-3}$ & $9.00 \times 10^{-3}$ & $1.46 \times 10^{-2}$ & $1.62 \times 10^{-3}$ & $5.00 \times 10^{-2}$ \\
\hline$k_{-3}\left(\mathrm{~mol}^{-2} \mathrm{~L}^{2} \mathrm{~s}^{-1}\right)$ & $1.17 \times 10^{-4}$ & $1.50 \times 10^{-5}$ & $1.05 \times 10^{-3}$ & $1.47 \times 10^{-4}$ & $1.50 \times 10^{-2}$ \\
\hline
\end{tabular}

(Figs. 6 and 7). Parameters were thus manually adjusted in order to correctly represent the evolution of the concentration of all compounds during reaction (Table 5).

This last model enables representation of general tendencies of the concentrations evolution of various oleic species present in the reaction medium. Experimental data points obtained by GC-FID are quite well represented by modelled tendencies with small uncertainties. These uncertainties may come from GC-FID measures (thus from material balance) and from the hypotheses emitted to build this model. Indeed, hypothesis concerning the absence of secondary reactions is debatable because oleic acid concentration can vary during reaction. However, this point was corrected by creating a pseudo-component for the model (see hypothesis (vii)). Moreover, although the mixture is biphasic only at the beginning of the reaction, the term of mass transfer was kept in all model equations throughout the reaction. The phenomenon of mixture is probably substituted by a diffusion phenomenon when the medium becomes monophasic. As the same model was kept throughout the reaction, that means diffusion is approximated by mass transfer.

Despite simplifying hypotheses, the model is satisfactory in the sense that it is able to predict all components concentrations under various experimental conditions (several ethanol to oil molar ratios and in diffusion or reaction mode).

The set of parameters obtained was compared with parameters of other works involving a transesterification reaction of vegetable oil with an alcohol homogeneously catalyzed (Poljanšek and Likozar, 2011). Table 6 and Table 7 show, respectively different mass transfer 
coefficients and sets of kinetics constants, obtained in batch reactor with an alcohol to oil molar ratio of 6.0 and various experimental conditions.

The mass transfer coefficient we established for transesterification reaction which is valid whatever the ethanol to oil molar ratio used and whatever the size of the tubular reactor $\left(1.0 \times 10^{-5} \mathrm{~m} / \mathrm{s}\right)$ is of the same order of magnitude as mass transfer coefficients (Table 6) calculated in various works of literature in spite of different processes (temperature, nature of catalyst, type of reactor).

It is quite difficult to compare rate constants (Table 7) of a work with another one because all experiments were carried out under different conditions. Moreover, the kinetics constants obtained from batch reactors often characterize apparent kinetics constants (including mass transfer and reactional phenomenon). Nevertheless, parameters we determined can approach more particularly the work of (Vicente et al., 2005), except our $k_{-1}$ constant, which is very different from other works of literature. Our $k_{-1}$ constant is very close to zero, which can be justified by the very small amount (or even the lack) of triglycerides at the end of the reaction. The simulator we have at our disposal is thus a robust tool which allows to model transesterification reactions in a very fast time.

\section{Using the model to simulate the separation of the products}

The model can be used to simulate different transesterification reactions, with other ethanol to oil molar ratios or in other reactors with higher or lower dimensions. Herein, the case study of products separation is presented. Indeed, it is possible to simulate the glycerol removal because it is a by-product of the reaction and its removal shifts the equilibrium towards products formation in order to maximize ethyl ester formation (trying to consume all triglycerides, diglycerides and monoglycerides). Two different cases were studied: one simulating a total glycerol removal from a removal time $t_{R}$ until the end of the reaction, and an other one simulating constant and continuous glycerol removal (i.e., a glycerol-removing flux $F_{G(\mathrm{R})}$ in $\mathrm{mol} / \mathrm{s}$ ) starting after a removal time $t_{R}$. These simulations were carried out for a transesterification reaction with an ethanol to oil molar ratio of 6.0 in a $1 / 16^{\prime \prime}$ PFA tube at $65^{\circ} \mathrm{C}$ but we could also have led them with other conditions because the set of parameters is valid whatever the molar ratio and the reactor size.

\subsection{Simulation of total glycerol removal}

First of all, a total glycerol removal was simulated, as it can be carried out at industrial scale in batch reactor (equivalent to a decantation): from $t_{R 1}$, a glycerol removal was set with a sufficient glycerol molar flux to eliminate the totality of glycerol present in the reaction medium. For $t>t_{R 1}$, glycerol was removed while forming. Fig. 8 illustrates a glycerol removal $\left(F_{G(\mathrm{R})}=0.5 \mathrm{~mol} / \mathrm{s}\right)$ from a reaction time $t_{R 1}=500 \mathrm{~s}$.

On Fig. 8, glycerol removal is visible (without optimization of $t_{R}$ ), diglycerides and monoglycerides concentrations decrease while ethyl ester concentration increases. This is due to the equilibrium shift towards consumption of reaction intermediates and thus, the system tends to the maximum ethyl ester concentration $\left([\mathrm{EE}]_{\max }=1.98 \mathrm{~mol} / \mathrm{L}\right)$. Maximum yield of $100 \%$ could be reached with such a system.

\subsection{Simulation of a constant and continuous glycerol removal}

Glycerol removal can also be simulated with a constant and continuous flux from a given time $t_{R}$. On one hand, if we proceed to the glycerol removal from $t_{R 2}$ using a flux lower than the glycerol formation flux ( $F_{G \text { (formation) }}$ ), then glycerol concentration still increases until a limit time $t_{L}$. After $t_{L}$, glycerol removal flux becomes more important than glycerol formation flux and glycerol concentration starts to decrease until reaching a zero value (for reaction time $t_{G=0}$ ). On the other hand, if we proceed to the glycerol removal from $t_{R 3}$ using a flux higher than glycerol formation flux, then glycerol concentration decreases continuously from $t_{R 3}$ to $t_{G=0}^{\prime}$, when glycerol concentration becomes null. These two cases are illustrated on Fig. 9 ((a): for $t=t_{R 2}, F_{G(\mathrm{R})}<$ $F_{G \text { (formation) }}$ and (b): for $t=t_{R 3}, F_{G(\mathrm{R})}>F_{G \text { (formation). }}$ ).

The goal of continuous glycerol removal is to shift equilibrium, as in previous paragraph 4.1 , in order to form a maximum of ethyl esters. If the main objective is to reach a certain glycerol removal or to minimize the removal time, a parameter optimisation on glycerol flux and/or removal time, for example, has to be carried out. Obviously, the simulator is usable for other objectives.

Moreover to validate the simulation work, experiments of continuous separation have to be managed. Indeed, polymer (Saleh et al., 2010) or ceramic (Wang et al., 2009; Gomes et al., 2010) membranes are used inside microreactors or millireactors

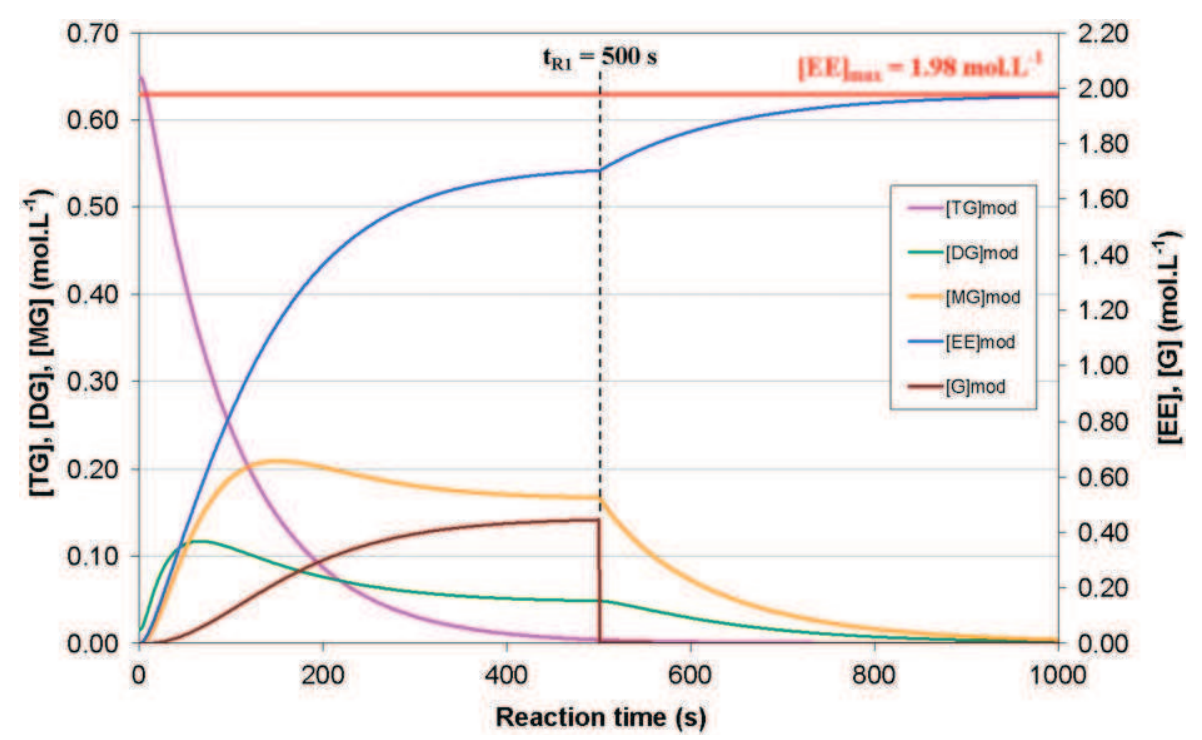

Fig. 8. Simulation of a total glycerol removal from $t_{R 1}=500 \mathrm{~s}$ during transesterification reaction (ethanol to oil molar ratio=6.0, 1 wt $\%$ EtONa, $65{ }^{\circ} \mathrm{C}, 1 / 16^{\prime \prime} \mathrm{PFA}$ tubes). 

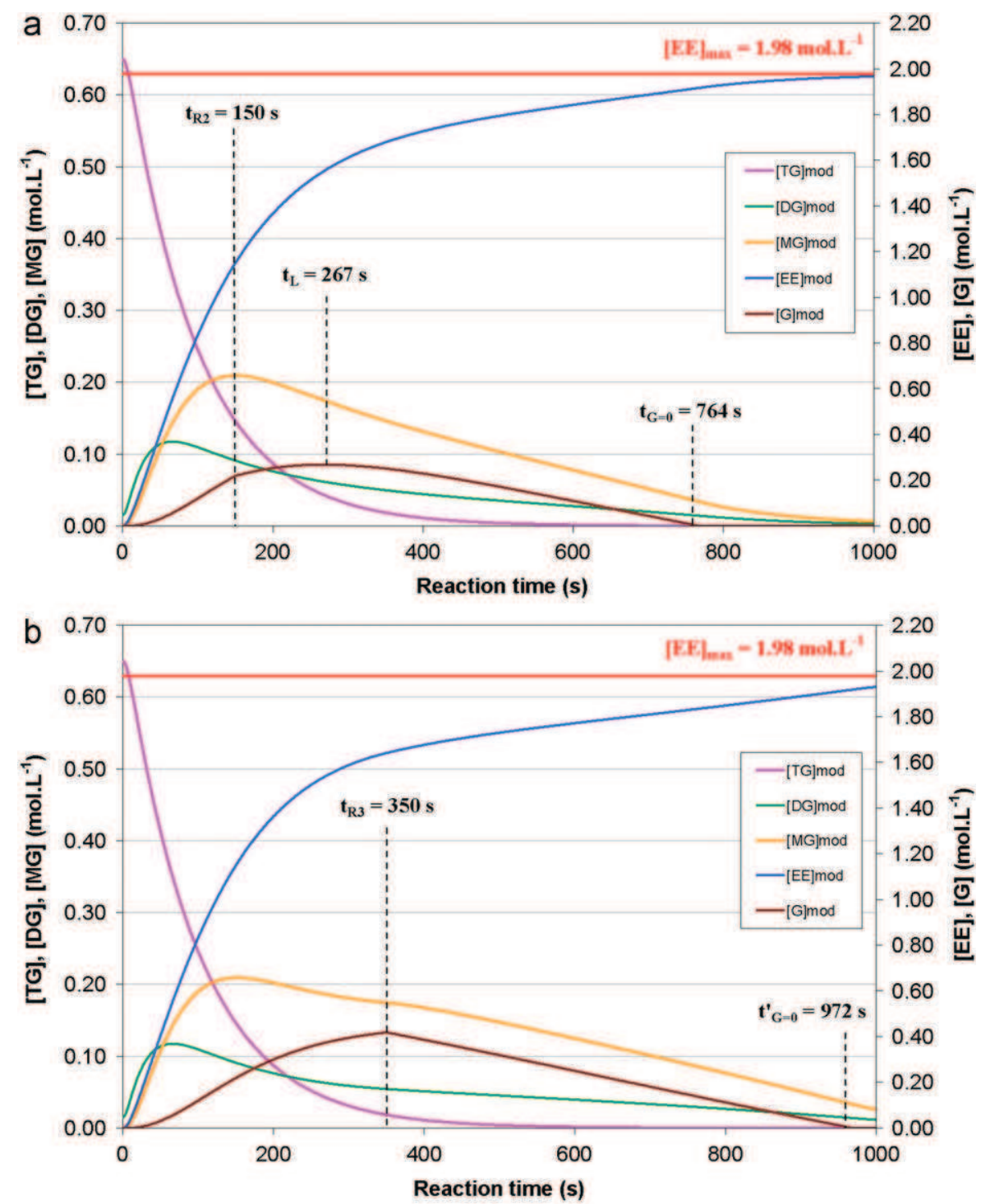

Fig. 9. Simulation of constant and continuous glycerol removals with $F_{G(R)}=0.001 \mathrm{~mol} / \mathrm{s}$ during transesterification reaction (ethanol to oil molar ratio $=6.0$, $1 \mathrm{wt} \%$ EtONa, $65^{\circ} \mathrm{C}, 1 / 16^{\prime \prime}$ PFA tubes): (a) glycerol removal from $t_{R 2}=150 \mathrm{~s}$ and (b) glycerol removal from $t_{R 3}=350 \mathrm{~s}$.

in order to selectively separate the two reaction products according to the physico-chemical properties of membranes.

\section{Conclusions}

In this work, a model able to represent both mass transfer phenomenon and reaction kinetics at a given temperature $\left(65^{\circ} \mathrm{C}\right)$ for the transesterification reaction between high oleic sunflower oil and ethanol was built. A set of kinetics parameters was determined in order to represent the evolutions of concentrations of different compounds (reactants and products but also reaction intermediates) whatever the ethanol to oil molar ratio and whatever the limiting phenomenon: chemical kinetics in microreactors (1/16" PFA tubes) and mass transfer in millireactors ( $1 / 8^{\prime \prime}$ PFA tubes). Moreover, this model is useful to simulate other reaction conditions. We simulated as an example the continuous removal of glycerol where ethyl ester reaches a maximum yield in a minimum of time. Various possible scenarios (total glycerol removal or constant and continuous glycerol removal) to modify the displacement of reaction equilibrium were studied. Optimization of parameters such as glycerol removal flow rate or removal time has to be carried out. A comparison between simulation results and real experimental data from separations with membranes would be interesting in a future work.

\section{Acknowledgements}

We gratefully acknowledge the co-financial support from INRA (Institut National de la Recherche Agronomique) and the Région Midi-Pyrénées in France which enabled us to lead this research work in the Laboratoire de Chimie Agro-industrielle (LCA) and the Laboratoire de Génie Chimique (LGC).

\section{References}

Bambase, M.E., Nakamura, N., Tanaka, J., Matsumura, M., 2007. Kinetics of hydroxide-catalyzed methanolysis of crude sunflower oil for the production of fuel-grade methyl esters. J. Chem. Technol. Biotechnol. 82, 273-280.

Darnoko, D., Cheryan, M., 2000. Kinetics of palm oil transesterification in a batch reactor. J. Am. Oil Chem. Soc. 77, 1263-1267.

Demirbas, A., Karslioglu, S., 2007. Biodiesel production facilities from vegetable oils and animal fats. Energy Sources Part A 29, 133-141. 
Encinar, J.M., González, J.F., Rodríguez-Reinares, A., 2007. Ethanolysis of used frying oil. Biodiesel preparation and characterization. Fuel Process. Technol. $88,513-522$.

Frascari, D., Zuccaro, M., Paglianti, A., Pinelli, D., 2009. Optimization of mechanical agitation and evaluation of the mass-transfer resistance in the oil transesterification reaction for biodiesel production. Ind. Eng. Chem. Res. 48, 7540-7549.

Freedman, B., Pryde, E.H., Mounts, T.L., 1984. Variables affecting the yields of fatty esters from transesterified vegetable-oils. J. Am. Oil Chem. Soc. 61, 1638-1643.

Fukuda, H., Kondo, A., Noda, H., 2001. Biodiesel fuel production by transesterification of oils. J. Biosci. Bioeng. 92, 405-416.

Gomes, M.C.S., Pereira, N.C., Barros, S.T.D.d., 2010. Separation of biodiesel and glycerol using ceramic membranes. J. Membr. Sci. 352, 271-276.

Guan, G., Teshima, M., Sato, C., Mo Son, S., Faisal Irfan, M., Kusakabe, K., Ikeda, N., Lin, T.J., 2010. Two-phase flow behavior in microtube reactors during biodiesel production from waste cooking oil. AIChE J. 56, 1383-1390.

Klofutar, B., Golob, J., Likozar, B., Klofutar, C., Žagar, E., Poljanšek, I., 2010. The transesterification of rapeseed and waste sunflower oils: mass-transfer and kinetics in a laboratory batch reactor and in an industrial-scale reactor/ separator setup. Bioresour. Technol. 101, 3333-3344.

Kouzu, M., Hidaka, J.-s., 2012. Transesterification of vegetable oil into biodiesel catalyzed by CaO: a review. Fuel 93, 1-12.

Marjanović, A.V., Stamenković, O.S., Todorović, Z.B., Lazić, M.L., Veljković, V.B., 2010. Kinetics of the base-catalyzed sunflower oil ethanolysis. Fuel 89 665-671.

Meher, L.C., Vidya Sagar, D., Naik, S.N., 2006. Technical aspects of biodiesel production by transesterification - a review. Renewable Sustainable Energy Rev. 10, 248-268.

Noureddini, H., Zhu, D., 1997. Kinetics of transesterification of soybean oil. J. Am. Oil Chem. Soc. 74, 1457-1463.

Poljanšek, I., Likozar, B., 2011. Influence of mass transfer and kinetics on biodiesel production process. Mass transfer in multiphase systems and its applications. M El-Amin. Ljubljana, InTech, 433-458.
Qiu, Z., Zhao, L., Weatherley, L., 2010. Process intensification technologies in continuous biodiesel production. Chem. Eng. Process. 49, 323-330.

Richard, R., Li, Y., Dubreuil, B., Thiebaud-Roux, S., Prat, L., 2011. On-line monitoring of the transesterification reaction between triglycerides and ethanol using near infrared spectroscopy combined with gas chromatography. Bioresour. Technol. 102, 6702-6709.

Saleh, J., Tremblay, A.Y., Dubé, M.A., 2010. Glycerol removal from biodiesel using membrane separation technology. Fuel 89, 2260-2266.

Sharma, Y.C., Singh, B., 2008. Development of biodiesel from karanja, a tree found in rural India. Fuel 87, 1740-1742.

Sharma, Y.C., Singh, B., Upadhyay, S.N., 2008. Advancements in development and characterization of biodiesel: a review. Fuel 87, 2355-2373.

Srivastava, P.K., Verma, M., 2008. Methyl ester of karanja oil as an alternative renewable source energy. Fuel 87, 1673-1677.

Stamenković, O.S., Todorović, Z.B., Lazić, M.L., Veljković, V.B., Skala, D.U., 2008. Kinetics of sunflower oil methanolysis at low temperatures. Bioresour. Technol. 99, 1131-1140.

Stamenković, O.S., Veljković, V.B., Todorović, Z.B., Lazić, M.L., Banković-Ilić, I.B., Skala, D.U., 2011. Modeling the kinetics of calcium hydroxide catalyzed methanolysis of sunflower oil. Bioresour. Technol. 101, 4423-4430.

Sun, J., Ju, J., Ji, L., Zhang, L., Xu, N., 2008. Synthesis of biodiesel in capillary microreactors. Ind. Eng. Chem. Res. 47, 1398-1403.

Sun, P., Wang, B., Yao, J., Zhang, L., Xu, N., 2009. Fast synthesis of biodiesel at high throughput in microstructured reactors. Ind. Eng. Chem. Res. 49, 1259-1264. Vicente, G., Martínez, M., Aracil, J., Esteban, A., 2005. Kinetics of sunflower oil methanolysis. Ind. Eng. Chem. Res. 44, 5447-5454.

Wang, Y., Wang, X., Liu, Y., Ou, S., Tan, Y., Tang, S., 2009. Refining of biodiesel by ceramic membrane separation. Fuel Process. Technol. 90, 422-427.

Wen, Z., Yu, X., Tu, S.-T., Yan, J., Dahlquist, E., 2009. Intensification of biodiesel synthesis using zigzag micro-channel reactors. Bioresour. Technol. 100, 3054-3060.

Xie, T., Zhang, L., Xu, N., 2012. Biodiesel synthesis in microreactors. Green Process Synth. 1, 61-70. 